\section{PAX 6 is normal in most cases of Peters' anomaly}

\begin{abstract}
Mutations in the PAX 6 gene are known to cause many cases of inherited and sporadic aniridia. Although embryologically similar to aniridia, the cause of Peters' anomaly has received far less attention. Two reports have been published demonstrating mutations in the PAX 6 gene in Peters' anomaly. We have analysed the PAX 6 gene in 15 individuals with Peters' anomaly ( 7 familial, 8 sporadic). This is the largest cohort of Peters' anomaly described. The $P A X 6$ gene was screened using a combination of single-strand conformational polymorphism gel electrophoresis and direct sequencing. No mutations were found in the coding region of the $P A X 6$ gene. We feel that Peters' anomaly is a heterogeneous condition and that for the majority of cases $P A X 6$ is not the 'Peters' anomaly gene'.
\end{abstract}

Key words PAX 6, Peters' anomaly

\section{Introduction}

Peters' anomaly is a congenital abnormality affecting the anterior segment of the eye. Both eyes are usually affected. The striking feature is corneal opacification, which may be central or peripheral, with underlying defects in the posterior stroma, Descemet's membrane and endothelium. There are frequently iris synechiae to the periphery of the opacity and less commonly keratolenticular strands. It is generally accepted that $50 \%$ of affected individuals will develop glaucoma in childhood.

Embryologically Peters' anomaly is thought to arise as a result of defective neural crest cell migration in the sixth to eighth weeks of fetal development during which the anterior segment of the eye forms. ${ }^{1}$ The $P A X 6$ gene has been implicated in the control of neural crest cell migration, with mutations giving rise to characteristic ocular phenotypes. Heterozygous nonsense mutations in $P A X 6$ are responsible wor many cases of sporadic and familial aniridia, as a result of haploinsufficiency. ${ }^{2}$ It has been proposed that missense mutations, where the protein is translated but with one amino acid substitution, may give rise to a variety of eye conditions such as Peters' anomaly, atypical aniridia or foveal hypoplasia. ${ }^{3}$ There have, however, only been two reports in the literature linking Peters' anomaly and $P A X 6^{4,5}$

The purpose of this study was to determine whether any $P A X 6$ mutations could be found amongst 15 individuals with Peters' anomaly.

\section{Patients and methods}

Ethics approval was obtained from the Leeds (East) Medical Research (Ethics) Committee. Affected individuals and family members were contacted by letter inviting their participation in this study.

All those who accepted were seen in their local eye department and, after a full discussion about the research, underwent an eye examination using a slit-lamp biomicroscope, in addition to gonioscopy, applanation tonometry and fundoscopy where appropriate. A blood sample was collected into a tube containing EDTA, and anterior segment photographs were taken where possible. When the individual was too young for a detailed exmination in the clinic this was performed under anaesthesia when it was next indicated for clinical reasons. A total of 15 individuals were examined; 7 had probable familial Peters' anomaly (from 4 families) and 8 were sporadic cases.

DNA was extracted from blood using standard methods. The $P A X 6$ coding region (exons 4-13, including exon 5a) was amplified using previously described polymerase chain reaction (PCR) primers.' Mutation analysis was performed using a combination of singlestranded conformational polymorphism (SSCP) gel electrophoresis and direct sequencing. A Hoeffer SE 600 series vertical gel electrophoresis unit was used for the SSCP with $18 \mathrm{~cm} \times 16 \mathrm{~cm}$ glass plates, $1 \mathrm{~mm}$ spacers and a square-toothed comb. All gels were run at $4{ }^{\circ} \mathrm{C}$ at a constant current depending on the size of the PCR product (range 16-20 mA). Silver staining was used to visualise the bands. PCR and SSCP conditions are shown in Table 1.

Direct sequencing was performed on fragments producing an abnormal banding pattern on SSCP analysis. Some random fragments were also sequenced from purified

\section{A.J. Churchill \\ A.P. Booth \\ R. Anwar \\ A.F. Markham}

Department of Molecular Medicine and

Ophthalmology Clinıcal Sciences Building St James's University Hospital

Leeds LS9 7TF, UK

e-mail: rmrajc@leeds.ac.uk 
Table 1. PCR and SSCP conditions

\begin{tabular}{|c|c|c|c|c|}
\hline \multirow[b]{2}{*}{ Exon } & \multirow{2}{*}{$\begin{array}{l}\text { PCR annealing } \\
\text { temp. }\left({ }^{\circ} \mathrm{C}\right)\end{array}$} & \multirow{2}{*}{$\begin{array}{l}\text { PCR product } \\
\text { size }(\mathrm{bp})\end{array}$} & \multicolumn{2}{|c|}{$\begin{array}{l}\text { SSCP conditions } \\
\text { run at } 4^{\circ} \mathrm{C}\end{array}$} \\
\hline & & & $(\mathrm{mA})$ & (h) \\
\hline 4 & 58 & 154 & 16 & 16 \\
\hline 5 & 56 & 260 & 19 & 16 \\
\hline $5 a$ & 50 & 216 & 19 & 17 \\
\hline 6 & 60 & 299 & 19 & 15 \\
\hline 7 & 60 & 253 & 19 & 17 \\
\hline 8 & 58 & 371 & 20 & 15 \\
\hline 9 & 56 & 206 & 19 & 15 \\
\hline 10 & 54 & 241 & 19 & 16 \\
\hline 11 & 60 & 206 & 19 & 16 \\
\hline 12 & 54 & 227 & 20 & 16.5 \\
\hline 13 & 54 & 135 & 15 & 15 \\
\hline
\end{tabular}

PCR products with $\left[\gamma^{32} \mathrm{P}\right] \mathrm{ATP}$ and polynucleotide kinase to end-label the PCR primers. A T7 DNA polymerase Sequenase Version 2 kit was used to sequence the PCR products in both the forward and reverse directions. All sequencing gels were fixed and dried before being exposed to X-ray film overnight at room temperature.

Two individuals had cytogenetic analysis performed. The remaining individuals were genotyped for a polymorphic marker in intron 8 of the $P A X 6$ gene to ensure that complete loss of one PAX 6 allele was not the cause of Peters' anomaly in these cases.

\section{Results}

The clinical details are summarised in Table 2 and the typical anterior segment features are shown in Fig. 1. Corneal scarring is the most striking feature in all cases. Fig. 2 shows the pedigrees of the probable familial cases. In family $A$, the father has bilateral Rieger's anomaly and the son has bilateral Peters' anomaly. In family B the parents are first cousins and have had 3 sons with microphthalmia and microcornea. Only one son remains alive and he has features of microphthalmia, microcornea and bilateral Peters' anomaly. Family $\mathrm{C}$ is a large

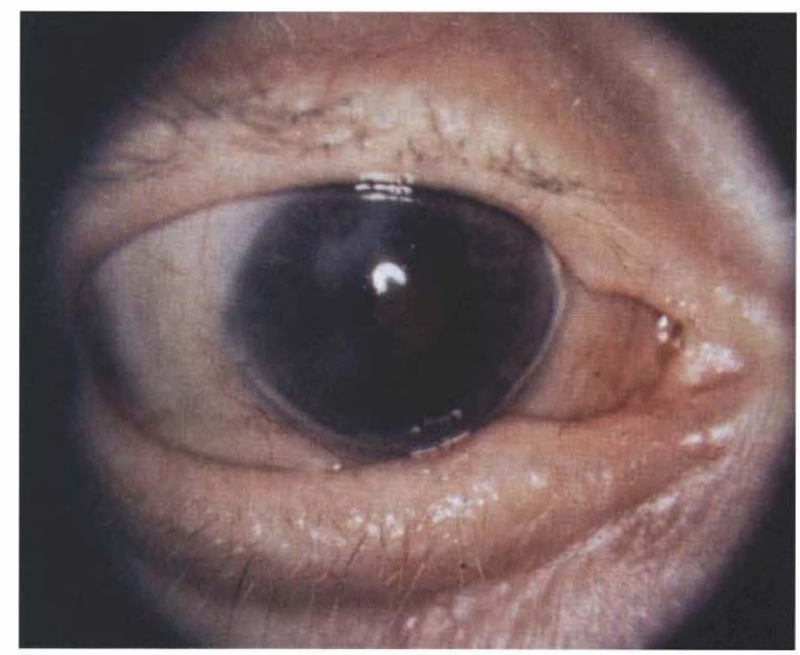

Fig. 1. Clinical features of the anterior segment of individual LAS de'monstrating the gross cormeal scarring characteristic of Peters' anomaly. Both e'ye's were e'qually affected.

dominant Peters' anomaly pedigree; 5 members have been examined (LAS, HAT, SHS, SYG and ALG) but only 3 consented to have blood taken. Family D were unusual in that both affected individuals had sparse hair, and nail and tooth abnormalities. Cytogenetics was performed on AUK and CHK and revealed no abnormalities.

Genotyping of a polymorphic marker from intron 8 confirmed heterozygosity in 9 of the remaining 13 individuals. This means that in 11 of 15 individuals Peters' anomaly cannot be explained as being due to complete loss of one PAX 6 allele.

PCR and SSCP analysis was successful in all 15 individuals and for all fragments in the $P A X 6$ coding region. SSCP analysis of the amplimer produced from primers $10 \mathrm{~F}$ and 10R demonstrated extra bands in 2 unrelated individuals. The banding pattern was identical and quite distinct from the norm (Fig. 3). Direct sequencing of these PCR fragments showed the same

Table 2. Clinical features of affected individuals

\begin{tabular}{|c|c|c|c|c|c|}
\hline Individual & $\begin{array}{l}\text { Corneal leucoma } \\
\text { with iris strands }\end{array}$ & Glaucoma & $\begin{array}{l}\text { Unilateral or } \\
\text { bilateral }\end{array}$ & $\begin{array}{l}\text { Sporadic or } \\
\text { familial }\end{array}$ & Other features \\
\hline MEW & Yes & No & Bilateral & Sporadic & Left congenital ptosis \\
\hline INH & Yes & No & Bilateral & Sporadic & Right congenital polar cataract \\
\hline JOM & Yes & Yes & Bilateral & Sporadic & Bilateral congenital cataracts \\
\hline HEL & Yes & No & Bilateral & Sporadic & Nil \\
\hline $\mathrm{JCO}$ & Yes & Yes & Unilateral & Sporadic & Nil \\
\hline NAR & Yes & Yes & Bilateral & Sporadic & Microphthalmia and retinal dysplasia \\
\hline DOM & Yes & No & Unilateral & Sporadic & Nil \\
\hline $\mathrm{THO}$ & Yes & No & Bilateral & Sporadic & Nil \\
\hline $\mathrm{ABR}$ & Yes & No & Bilateral & ?Familial (A) & Father has Rieger's anomaly \\
\hline ALS & Yes & No & Bilateral & ?Familial (B) & $\begin{array}{l}\text { Microphthalmia, microcornea and } \\
\text { consanguineous parents }\end{array}$ \\
\hline LAS & Yes & Yes & Bilateral & Familial (C) & Nil \\
\hline HAT & Yes & No & Bilateral & Familial (C) & Nil \\
\hline SHS & Yes & Yes & Bilateral & Familial (C) & Umbilical hernia \\
\hline AUK & Yes & Yes & Bilateral & Familial (D) & $\begin{array}{l}\text { Microphthalmia, partial maxillary } \\
\text { anadontia, sparse hair and nail pitting }\end{array}$ \\
\hline $\mathrm{CHK}$ & Yes & No & Bilateral & Familial (D) & $\begin{array}{l}\text { Poorly enamelled teeth, sparse hair } \\
\text { and nail pitting }\end{array}$ \\
\hline
\end{tabular}




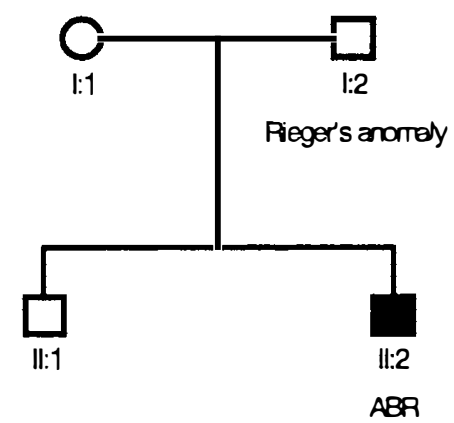

FAMILY C

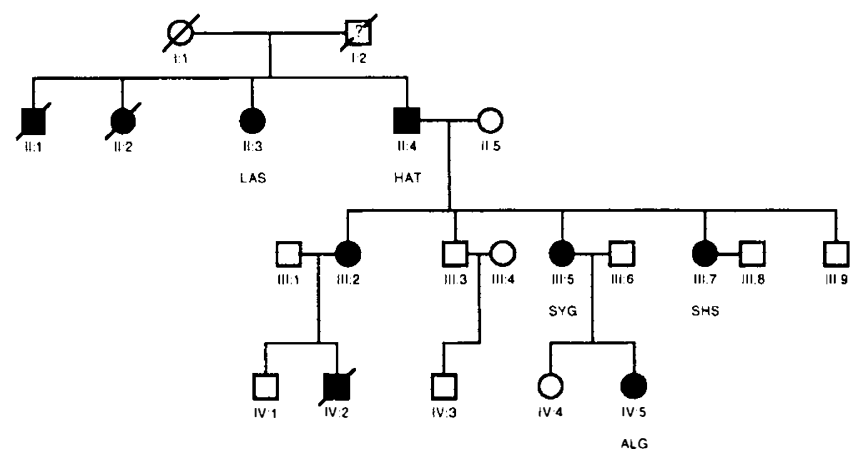

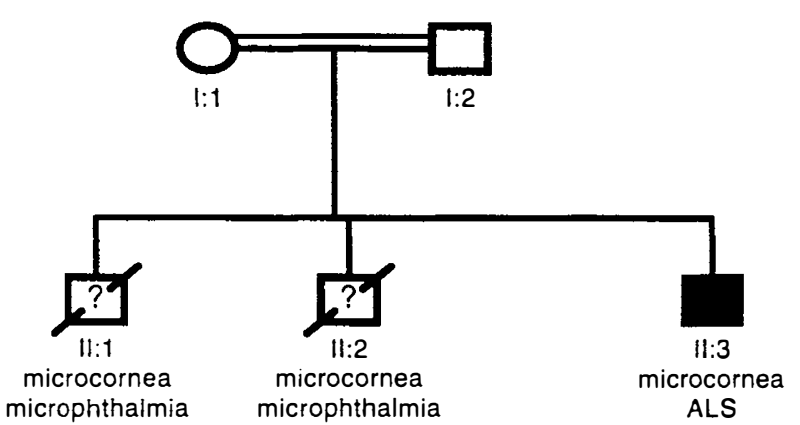

FAMILY D

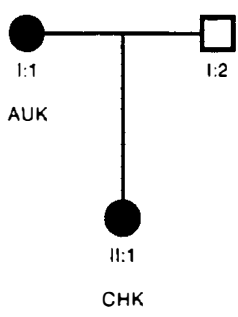

Fig. 2. Pedigrees of the familial cases of Peters' anomaly. See text for details.

single nucleotide change: a $\mathrm{C} \rightarrow-\mathrm{T}$ transition in one of the $P A X 6$ alleles at position -12 in intron 9 (Fig. 4). No exonic or splice site mutations were found in any of the fragments analysed. Random sequencing of fragments that showed normal SSCP banding patterns did not reveal any mutations.

\section{Discussion}

The PAX 6 gene is a member of the 'paired-box containing' gene family of which there are nine members: PAX 1-9. The protein contains two important DNAbinding domains: the paired and homeo domains. These confer the ability to bind to other regions of DNA, i.e. genes, and regulate their transcription. Two normal copies of the PAX 6 protein are required for normal ocular development. Presence of only one protein copy usually results in aniridia but has also been reported to cause autosomal dominant keratitis, both phenotypes being due to haploinsufficiency. ${ }^{7}$ Having two protein copies but with an altered amino acid composition has been shown to result in atypical aniridia and foveal hypoplasia. $^{3}$

There have been conflicting data as to whether mutations in the PAX 6 gene are responsible for most cases of Peters' anomaly. Two publications have demonstrated abnormalities in the $P A X 6$ gene: Hanson et al., ${ }^{4}$ described a family in which an arginine (basic) residue was replaced by glycine (neutral) at codon 26 . Two copies of the PAX 6 protein are produced but with an altered amino acid composition. This substitution occurs at the beginning of the paired domain and is hypothesised to disrupt the DNA-binding properties of the PAX 6 protein. They also described a sporadic case of Peters' anomaly with only one copy of $P A X 6$. However, the haploinsufficiency resulting from this would be expected to result in aniridia rather than Peters' anomaly.

Azuma et al. ${ }^{5}$ have described a missense mutation in exon $5 \mathrm{a}$, an alternative splice variant at the beginning of the paired domain, in a large pedigree with Peters' anomaly. They suggest a position-dependent effect of missense mutations whereby disruption at the beginning of the paired domain causes Peters' anomaly and disruption at the end of the paired domain results in foveal hypoplasia.

However, evidence that mutations in $P A X 6$ are not the main cause of Peters' anomaly is growing. Calvas et al. ${ }^{8}$ sequenced the entire $P A X 6$ coding region in 4 individuals with Peters' anomaly (2 familial and 2 sporadic) and found no mutations. We performed this study to determine whether $P A X 6$ mutations could be detected in any of 15 affected individuals. Whilst we cannot rule out the possibility of mutations in the promoter region as being the cause of Peters' anomaly, the data so far suggest that we should be looking for missense mutations in the coding region. It is accepted 


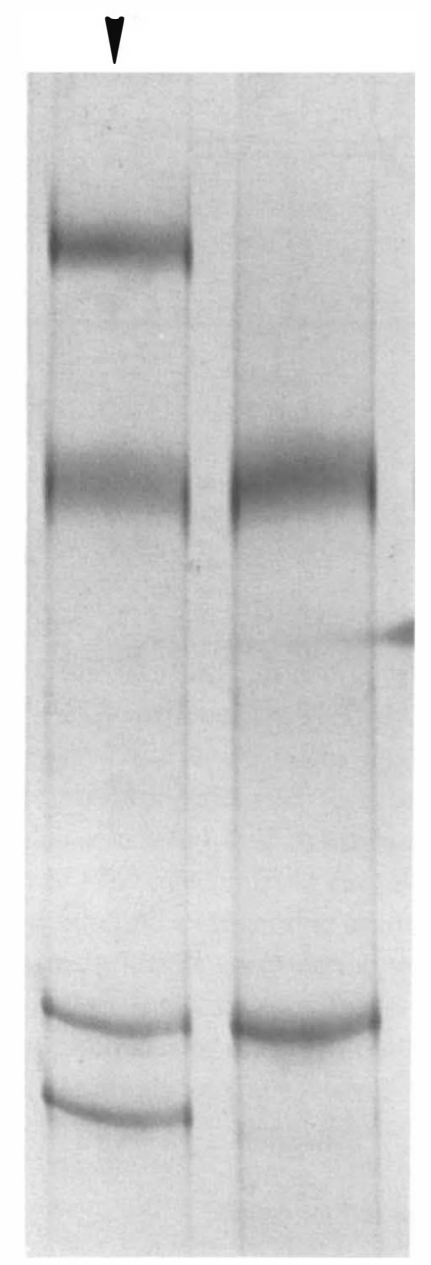

Fig. 3. SSCP of the PCR fragment amplified from the primer pair 10F/10R in two cases of sporadic Peters' anomaly. Two bands are usually seen representing the conformers of the two single strands of $D N A$. In the lane indicated by an arrow two extra bands are present suggesting a sequence change exists in the PCR fragment. The original conformers remain, indicating the sequence change is heterozygous in nature. that some cases of Peters' anomaly are probably due to genetic causes and may be secondary to events in utero, but we expected to find some mutations, particularly in the familial cases. We chose PCR-SSCP analysis because it is a rapid and efficient method for mutation detection. Hayashi and Yandell' reviewed the sensitivity of this method and found that, for fragment sizes ranging from 101 base pairs (bp) to $350 \mathrm{bp}$, between $80 \%$ and $100 \%$ of mutations could be detected. We have used this method successfully in the past to detect $P A X 6$ gene mutations in sporadic and familial aniridia cases. ${ }^{10}$

We have demonstrated an intronic base change at position -12 in intron 9 in 2 unrelated individuals with Peters' anomaly. This is thought to be a naturally occurring polymorphism since it has been observed in an unaffected individual and in aniridics who have been shown to have nonsense mutations elsewhere in the $P A X$ 6 gene (Richard Axton, MRC Human Genetics Unit, Edinburgh, personal communication). Polymorphisms of this nature are not uncommon and should not interfere with the translation of two normal copies of the PAX 6 protein.

We have analysed the coding region in 15 individuals with classic Peters' anomaly, the largest collection described, and can find no evidence of $P A X 6$ mutations. From this work, and the evidence to date, we must conclude that Peters' anomaly is a heterogeneous condition and that for the majority of cases $P A X 6$ is not the 'Peters' anomaly gene'.

This work was kindly supported by The Wellcome Trust, R.E.D. Trust and the British Medical Association. We thank the following clinicians for referring individuals with Peters' anomaly for inclusion in this research: $\mathrm{Mr} \mathrm{W}$. Church, Mr R. Doran, Professor J. Forrester, Mr F. Green, Mr J. Innes, $\mathrm{MrC}$. Rostron, Mr D. Tole and Mr G. S. Willetts.

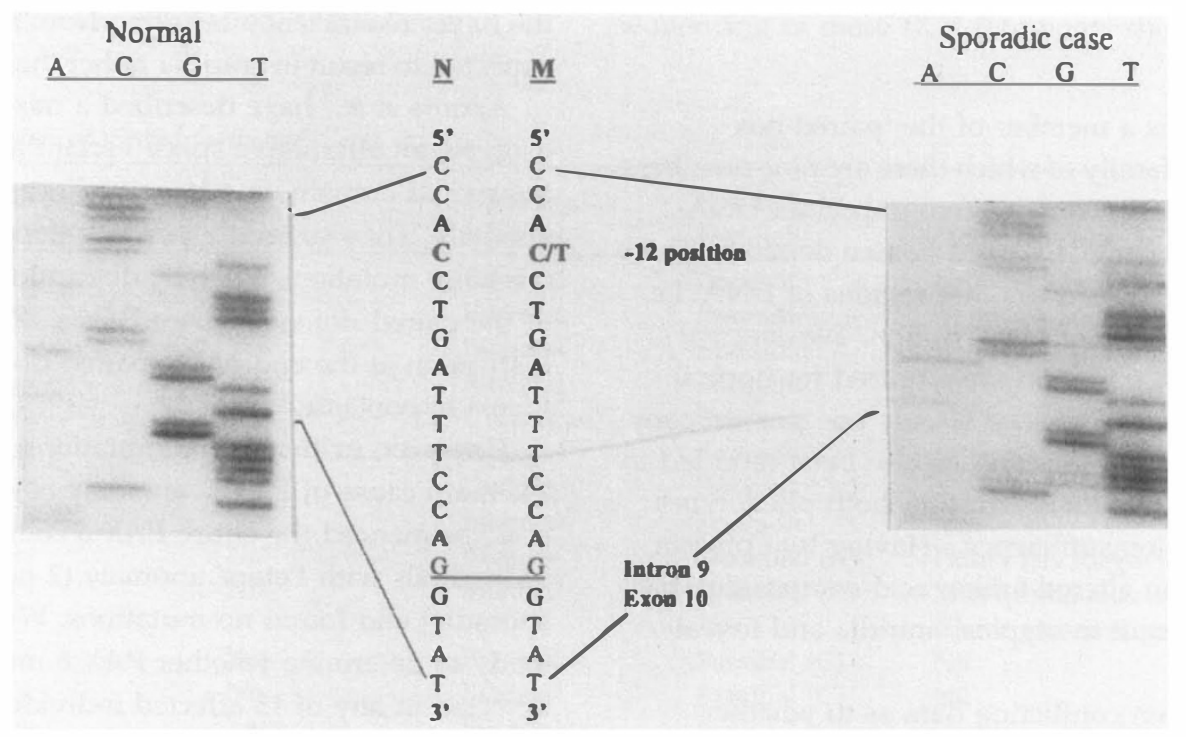

Fig. 4. Sequence analysis showing the heterozygous nucleotide change in intron 9 in a case of sporadic Peters' anomaly. The nucleotide at position -12 is heterozygous $C / T$ in the mutant $(M)$ form. The normal $(N)$ sequence is shown for comparison. The sequence change does not alter the coding sequence. 


\section{References}

1. Churchill AJ, Booth AP. The genetics of aniridia and anterior segment dysgenesis. Br J Ophthalmol 1996;80:669-73.

2. Fisher $E$, Scrambler P. Human haploinsufficiency: one for sorrow, two for joy. Nature Genet 1994;7:5-7.

3. Azuma N, Nishina S. PAX 6 missense mutation in isolated foveal hypoplasia. Nature Genet 1996;13:141-2.

4. Hanson IM, Fletcher J, Jordan T, Brown A, Taylor D, Adams $\mathrm{R}$, et al. Mutations at the $P A X 6$ locus are found in heterogeneous anterior segment malformations including Peters' anomaly. Nature Genet 1994;6:168-73.

5. Azuma N, Nishina S, Yamada M. Missense mutation in the $P A X 6$ gene in a family with anterior segment anomalies. Invest Ophthalmol Vis Sci (Suppl) 1997;38:A117.
6. Glaser T, Walton DS, Maas RL. Genomic structure, evolutionary conservation and aniridia mutations in the human PAX 6 gene. Nature Genet 1992;2:232-9.

7. Mirzayans F, Pearce WG, MacDonald IM, Walter MA. Mutation of the PAX 6 gene in patients with autosomal dominant keratitis. Am J Hum Genet 1995;57:539-48.

8. Calvas P, Rozet J-M, Gerber S, Munnich A, Kaplan J. Novel Pax 6 homeodomain mutations in congenital aniridia and identification of a new alternative splicing of PAX 6 mRNA. Am J Hum Genet (Suppl) 1996;59:A394.

9. Hayashi K, Yandell DW. How sensitive is PCR-SSCP? Hum Mutat 1993;2:338-46.

10. Churchill AJ, Anwar R, Markham AF. PAX 6, aniridia and Peters' anomaly. Invest Ophthalmol Vis Sci (Suppl) 1997;38:A112. 